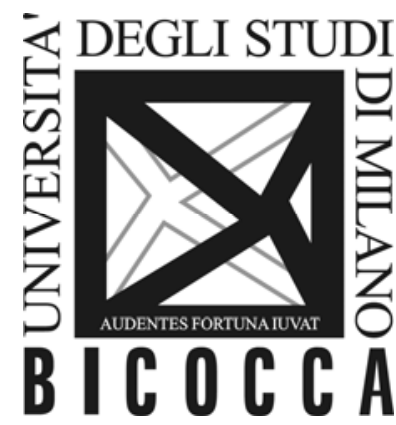

DEPARTMENT OF ECONOMICS

UNIVERSITY OF MILAN - BICOCCA

WORKING PAPER SERIES

Hierarchical contracting in grant decisions: ex-ante and ex-post evaluation in the context of the EURegional Policy

Michela Cella, Massimo Florio

No. 171 - June 2009

Dipartimento di Economia Politica

Università degli Studi di Milano - Bicocca

http://dipeco.economia.unimib.it 


\title{
Hierarchical contracting in grant decisions: ex-ante and ex-post evaluation in the context of the EURegional Policy*
}

\author{
Michela Cella ${ }^{\dagger} \quad$ Massimo Florio
}

June 2009

\begin{abstract}
This paper applies incentive theory to the context of the European Union (EU) Regional Policy. The core instruments of the policy are the Structural Funds, capital grants that flow from the European Commission (EC) to Member States and regional authorities to promote investment and growth at local level. The EU grants need a co-payment by the regional government and do not cover in full the investment cost. We model this situation, similar to several other supra- national or federal contexts, as a simple principal-supervisor-agent model of the investment game between a supranational player (the principal), such as the EC, a non (fully) benevolent regional government (the supervisor), and a private firm (the executing agency). We show how the role of providers of additional information, the region (ex-ante) and an evaluator (ex-post) is crucial to reducing the optimal value of the grant and to improving the inefficiencies caused by asymmetric information at the grant decision stage in a federal hierarchy

Keywords: Hierarchical contracting, project evaluation, EU Regional Policy JEL codes: D82, H77,R58
\end{abstract}

\footnotetext{
${ }^{*}$ We thank particpants at the SIEP Annual Meeting (2007) and anonymous referees for helpful comments. All remaining errors are our own.

${ }^{\dagger}$ University of Milan-Bicocca, michela.cella@unimib.it, mailing address: Dept. of Economics, Piazza Ateneo Nuovo 1, 20126 Milan (Italy)

${ }^{\ddagger}$ corresponding author, University of Milan, massimo.florio@unimi.it, mailing address: Dept. of Economics, Via Conservatorio 7, 20122 Milan (Italy)
} 


\section{Introduction}

This paper applies incentive theory to a hierarchy of contracts that is a typical feature of federations, where regional development policy competencies, including the co-funding of infrastructure through grants, are often decentralized and partly distributed between different levels of decision-making at national level. In this context, we contribute to the literature by modelling the optimal grant to an executing agency under a co-payment between a benevolent supra-national planner and a regional government with a private agenda. Under asymmetric information, we show a role for ex-ante and ex-post project evaluation respectively by the region and an auditor loyal to the supra-national planner.

A major example of this hierarchical contracting process is the regional policy of the European Union (EU). The core instruments are the Structural Funds. These are capital grants that involve a range of actors and coordination mechanisms between the European Commission (EC), the national and (sub) regional level (European Commission [2007]) and investing firms. Moreover, the implementation of specific tasks often involves several actors, including quasi-government bodies with supervisory roles. Typically an ex-ante project appraisal is delegated by the EC to the regional authorities, while the EC retains the right to send evaluators/monitors at a later stage (ex-post evaluation).

Similar hierarchical contracts can be observed with some loans or grants by the World Bank or other international organisations, including large NGOs that support local development projects. Countries with a federal governments often support infrastructure expenditures by matching funds at central, state and lower government level, with different supervisory and inspection roles.

In these complex environments, the policy decision maker acting as a (relatively)benevolent principal, the one who usually offers most of the investment funds as a grant, cannot simply rely on commands to efficiently implement his objectives. There is a need to provide incentives to stimulate adequate effort by different agents. Information asymmetry, rents and incentives are the key analytical concepts in this multi-agent context. We focus on the EU case because it offers a common infrastructure investment policy framework shared by its 27 members states, and because of the substantial amount of finance involved in the operations of the SF, around 350 billions Euro in 2007-2013, probably the largest investment plan in Europe after the post-war Marshal Plan. We think, however, that our model has a more general interest, because it applies to a large set of investment co-financing schemes under decentralized competencies with co-funding schemes. Thus, we shall interchangeably 
refer respectively to the EC or the supra-national planner, the region or the state, and our results can be easily transferred to similar contexts, with suitable adaptations.

In the paper we assume that the supra-national player is a benevolent social planner. This assumption,in our opinion, is justified by the fact that the EC is fairly independent from elected governments of the Member States, and because of its special composition and voting mechanism. This makes it relatively difficult for a majority coalition with a private agenda to capture the EC in major investment decisions. Similar reasoning (with some caution) applies e.g. to the World Bank as compared with its clients, or federal offices versus local constituencies. The EC has a mandate to implement a regional development policy. This is done by offering regional governments grants that are targeted to co-funding of infrastructure and other public investment. Second, regional governments, in contrast with the EC, are elected bodies. They have an objective function that combines social welfare maximization and the private agenda of the policy-makers. We do not assume that all regional governments are prone to corruption, but we consider realistic to think that policy makers across the regions are, to a certain extent, self interested. Moreover we assume, as previous literature does (in other contexts) that decentralised governments are potentially more informed, but differ in their ability to elicit or interpret signals. In this perspective, our model is closely related to Laffont (2005), who discusses regulatory mechanisms in developing countries under governments with a private agenda. We depart, however, from Laffont (2005) because of the co-funding mechanism (and other specific features).

The implementing agency can be seen as a firm under the control of a utilitymaximizing manager. This is more obvious when the firm is under private ownership, and is just a simplification of the model when the firm is fully or partly governmentowned. Project appraisal (ex-ante) is under responsibility of the region, because it would be too costly for the supra-national planner to acquire all the information on any potential projects. Thus, the regional authority screens the local project proposals, and select those to be proposed to the EC. We then introduce in the game a ex-post evaluator, acting loyally on behalf of the supra-national planner (an office or an independent agency). In fact, project ex-post evaluation is formally required by the EU regulations, and similar inspectors can be observed in many federations or international institutions. The World Bank, for example, has a division entirely devoted to ex-post project evaluation.

The game is as follows. The regional government identifies ex-ante a socially deserving project, that would be however unprofitable without a public subsidy. The 
EC offers then a matching grant to the regional government, who needs to cover the difference between the EU grant and the investment funding gap, i.e. the cost not recovered by future revenues. There are two technologies available to the implementing firm. If the firm claims that it has access to the less efficient technology, i.e. the investment cost is higher than otherwise, the EC may send an ex-post evaluator. If the evaluator discovers that the firm has lied, because in fact it had access to the superior technology, there will be a penalty. Moreover, the EC offers the regional government a reward for ex-ante evaluation in order to avoid collusion between the firm and the self-interested policy makers. We determine a)the incentive to be given to the region to disclose information;b)the optimal grant; c) the optimal amount of ex-post project evaluation that addresses the asymmetric information problem of the European principal. We take the co-payment of the grant between the EC and the regional authority as exogenous, e.g. fixed by a law or an international treaty.

Information providers have a crucial role in minimizing rents that accrue to firms and to self-interested policy makers, and well designed ex-ante and ex-post evaluation contracts should be essential ingredients of co-funding of infrastructure in a multigovernment setting, under an appropriate incentive mechanism for the grant decision.

The setting we describe is entirely new in the literature on hierarchical contracting, particularly because of the role of the co-funding mechanism and of project evaluation. We show that any investment grant scheme with cost-plus rules (as the one current adopted for the EU Structural Funds) is inefficient. We also show that some specific parameters, i.e. the efficiency of collusion between the regional managing authority and the firm, the precision of the signal about firm's efficiency in ex- ante project evaluation, the cost of ex-post evaluation determine the optimal grant. We argue that in an international setting these parameters are country or region specific, hence it is necessary to move away from grant schemes that are too rigid.

The paper has the following structure. Section 2 briefly discusses our research motivation and some earlier contributions. Section 3 offers some background information on the EU Regional Policy context, in order to make more explicit the intuition behind the model. Section 4 presents our model, and Section 5 concludes.

\section{Research motivation and earlier literature}

The approach we suggest in order to model an investment game between a supranational body, a regional government, and the executing firm, is related to earlier literature on hierarchical contracts when there is delegation of monitoring to a super- 
visor. We mention here (very) selectively some earlier frames, in order to show our research motivation, its relationship with other approaches that have been proposed, and our contribution.

Hierarchical contracting is a feature of many real life organizations, including governments and firms. It arises when a principal, heading an organization, does not retain full control on the contracting and communication relationships with the agents at lower levels of the hierarchy. This loss of control can take many forms (for an exhaustive taxonomy see Mookherjee [2006]) and involves different degrees of delegation of tasks to middlemen, supervisors or subcontractors. We are focusing on an environment in which the principal contracts with a manager (subcontractor) who is then in charge of contracting with the remaining agents.

This context is related to, but departs from, previous literature on fiscal federalism and grants in a federal environment under asymmetric information. While Bordignon et al (2001) or Bucovetsky et al (1998) focus on distorting local taxation, and lumpsum transfers under asymmetric information on tax bases between the federal state and regions, here we are going to focus on the expenditure side only, under a hierarchy of contracts, with a co-payment. We simply assume that optimal lump-sum taxes and transfers are not available, hence there is a marginal cost of public funds. Differently from Breuillè and Gary-Bobo (2007) we do not consider free mobility of citizens across regions in the Tiebout tradition. We also do not consider the redistribution objectives that motivate the papers by Lockwood (1999) or Cornes and Silva (2002).

Another possible approach to deal with a multi-government environment, as in the EU regional policy context, would be to follow Laffont and Tirole [1993] and Martimort $[1992,1999]$, in the framework of a theory of multi-principals, where different incentive mechanisms compete with each others. In fact, the EU is indeed an array of several government bodies (the EC, the national and regional governments, etc.) and they regulate different entities (e.g. municipalities, private firms, etc.). The competencies in regional policy are, however, usually different in each layer of government, and the total amount of EU grants (the Structural Funds) allocated to each Member State and region are set ex ante by budgetary decisions (inter-governmental agreements). Hence, there are no competing contracts, and a multi-principal framework does not seem appropriate to our problem. Nevertheless, different regulators need to concur in some decisions, and we want to model this aspect of partial decentralization. Caillaud, et al [1996] study public decision-making when local authorities offer incentive contracts to local agents, in a context of asymmetric information. Their model refers explicitly to incentive policy in the EU context, and they assume, as 
we do, that national authorities have better information on their agents, but less bargaining power than central authorities at the community level. This may justify the delegation of tasks to regional governments by the EC. We depart from their model because of we introduce the co-payment mechanism and we also consider the role of project evaluation. Huber and Runkel (2006) consider an environment, where there is a federation with two types of local governments and a central government, with the former differing in the cost of providing public goods. Under asymmetric information, the authors show which types of grants are second- best. They show why, in particular, unconditional grants are always inefficient in their context. The types of grant offered in order to implement industrial policies is discussed by Wren [2003]. He considers discretionary industrial assistance schemes, when there is an uninformed government and a uniform distribution of firms with differing unit costs. Discretion in this context is a kind of project screening device, in order to learn the type and to reduce the 'informational rents' of automatic assistance. In our paper, to simplify, we assume that there is only one contract type, and the screening function is assigned to the regional government who is supposed to know better than the EC the firm characteristics. Melumad et al [1995] offer a model where the principal delegates to some agents in a hierarchy the authority to communicate and contract with agents at lower levels. They show the benefits and costs of delegation, and find that monitoring and a specific sequence of contracts are necessary for delegation to achieve second-best results. In our framework, we get a similar result by the parallel evaluation and co-funding contracts between principal and regional government, the contract between the latter and the firm, and ex-post evaluation by an inspector sent by the principal.

One aspect we are interested in, is the potential impact on the game solution of a penalty if ex-post evaluation discovers that the firm was not of the low efficiency type in our context. There are many possible approaches on this issue. For example, De Marzo et al [2005] show that self-regulation in some professions can be seen as the delegation by government of enforcing antifraud rules to an organization. They model contracting and enforcement as a two-tier problem. First the delegated regulator chooses its enforcement policy, i.e. the probability of investigations and a penalty schedule. Under such arrangements agents compete by offering contracts to their customers. Interestingly they conclude that the threat of government enforcement leads to more enforcement by the regulatory body of the profession, and this preempts any government enforcement. This has some resemblance with the subsidiarity principle at the EU level, where the role of the EC is seen as a complement to the role 
of the Member States, and it is perceived that the mere existence of EC investigation powers offer to the MS an incentive to discover frauds in their constituency in order to avoid EC anti-fraud initiatives.

More recently Akai and Silva (2009) discuss the 'soft budget syndrome' in federations, where a central government offers additional capital to a regional body in order to prevent a performance failure by the latter. Ex-post perfect information is needed to cure soft budgets, and this offers an incentive for the region to reveal its information. Their problem is clearly related to ours, even if in a different context, because we have co-payment built in our mechanism.

Finally, our approach is more closely related to Laffont [2005], where he discusses a situation where policy-makers in less developed countries have a private agenda, regulators can be corrupted, and where ex post evaluation to monitor the outcome of a decision (a privatization, i.e. a public divestiture) is costly. We consider that regional governments in some member states of the EU, particularly in regions lagging behind, are not (fully) of the benevolent type, and try at the same time to maximize the welfare of their constituency, but also they want to extract some private benefits from the contracts with the agents. We look at public investment as similar to privatization, because usually the firm involved in building an infrastructure is a private one, and can try to bribe the regional government. In the Laffont model there is ex-post evaluation, but we add to the hypothesis that this evaluator is sent by the EC, a benevolent government (perhaps just because of the mutual countervailing power of the many governments that appoint it). Before turning to the model, in the next section we briefly give some background information about the EU regional policy context .

\section{Infrastructure co-financing under the EU regional policy}

In 2007-2013 the EU Structural Funds will contribute with matching grants to the investment plans of 27 countries, including 12 new members (mostly former transition economies). The EU seven-years budget supporting this effort will draw from a provision of around EUR 350 billion for Cohesion policy. A substantial part of the grants is going to be allocated to infrastructure projects, in regions lagging behind in their endowment of basic stock of capital compared to the rest of the EU. Moreover, there will be a leverage effect of the EU funds on public and private finance, because in most cases Brussels will contribute only a part of the cost, and the rest of capital 
expenditure must be matched by other sources of finance.

Ceilings for EU co-financing are different according the region and the fund (the overall 'macroeconomic' cap at national level for EU grants is $4 \%$ of GDP per year). In this paper we focus on revenue generating public projects.

According to Art. 55 of the EU Structural Funds regulation, these are defined as: any operation involving an investment in infrastructure the use of which is subject to charges born directly by users or any operation involving the sale or rent of land or buildings or any other provision of service against payment.

For these projects the EC contributes to filling the gap between the present value of investment costs and the present value of the net revenues by the approval of an EU grant. We turn now to explaining the current mechanism and its problems. Similar problems arise in other contexts, including some US federal programmes, and some international assistance schemes for local development, but we do not review them here.

Project selection and ex-ante evaluation within this regional policy framework is normally the sole responsibility of the national authorities. However for very large projects (with a total investment cost of more than EUR 50 million, or 25 for environmental projects), the EC requires Member States to submit a cost-benefit analysis (CBA) and then takes a specific co-financing decision, (European Commission,2006).

In addition to relying on the governments of the Member States to acquire this information and ex-ante project evaluation, the SF regulations state that the EC is responsible for ex-post evaluation: it can appoint experts that after the completion of the project will re-assess its benefits and costs. Art 49 of the above mentioned regulation states that:

'The Commission shall carry out an ex post evaluation for each objective in close cooperation with the Member States and managing authorities. Ex post evaluation shall cover all operational programmes under each objective and examine the extent to which resources were used, the effectiveness and efficiency of Fund programming and the socioeconomic impact...'.

Hence, there is a clear provision for ex-ante and ex-post evaluation in the SF regulations, but there is, however, no clear link between the investment co-financing decision and such evaluations (except when fraud is discovered). Florio and Vignetti [2006] suggest that without a 'contractual' link between evaluation and co-financing, a misallocation of Structural Funds may arise, and offer evidence of this. 
In principle, projects expecting a positive financial net present value have no funding gap and thus do not generally receive a grant from the EU (although special rules apply to productive investments under state aid regimes, e.g. EU subsidies to building communication or energy networks).

The rationale of the 'funding-gap' approach is to determine the project's selffinancing ratio so as to grant, in principle, to the investor not less and no more than what is actually needed to implement a socially beneficial, but financially loss-making project. The problem with the 'funding gap' approach is obvious: the applicant has a clear incentive to exaggerate expected costs and to underestimate revenues, to maximize the grant.

Given the ceilings, the remaining of the funding gap, i.e. the project cost not filled in by the EU grant, is covered by a matching grant by the Member State (MS). Because member states are often under strict budgetary constraints, they have an incentive to collude with the implementing agency to obtain a larger EU grant. The member states, however, cannot subscribe any loss-making project, because, if the funding gap exceeds the grant ceiling, they have to contribute the difference.

Unfortunately, however, under asymmetric information the 'wrong incentive' problem is still in place, because it is not clear to what extent the national or regional governments will not collude with the investors in trying to extract a larger rent from the granting mechanism. We suggest below a framework for the analysis of this hierarchical contracting problem, and we solve it.

\section{The model}

\subsection{Utility functions and the full-information solution}

As previously discussed the European Commission wants to finance an indivisible project in one of the member states which is not financially viable without government intervention. The project has a positive economic net present value but a negative financial net present value that makes the project non profitable for a private firm. A grant covering the difference between revenues and investment plus operating costs would allow the firm to carry out the project without a loss.

Since EU funding are limited the goal of the Commission is to finance projects with the minimum expenditure necessary, that is the one that guarantees the participation of the firm while maximizing social benefits.

In other words if the return from the projects are given by the operating revenues 
$R$ we have a situation where, without a grant:

$$
R-\text { TotalCosts }<0,
$$

while with a grant the total profits become non negative:

$$
R+G R A N T-\text { TotalCosts } \geq 0 .
$$

We assume the cost function of the firm is given by:

$$
\begin{aligned}
\text { TotalCosts } & =c+K \\
& =\beta-e+K
\end{aligned}
$$

where $K$ is the cost of capital which is common knowledge, $c=\beta-e$ is the operating cost which is composed of a firm specific characteristics $\beta$ that is private information to the firm and an unobservable effort level $e$ which reduces the cost.

For each level of effort $e$ the firm must endure a disutility $\psi(e)$ (where $\psi^{\prime}>0$, $\left.\psi^{\prime \prime}>0\right)$.

$\beta$ is an adverse selection parameter that indicates the level of efficiency of the firm, we assume it can take two values $\bar{\beta}$ and $\beta$ with $\bar{\beta}>\beta$. We assume that $\Delta \beta$ is not too large, so that it will always be socially beneficial to require production from both types of firms. It is independently distributed with $\nu=\operatorname{Pr}(\beta=\underline{\beta})$ and the distribution is common knowledge. $e$ is non-negative and is a moral hazard variable which is decided by the firm after the grant has been approved and is also private information to the firm.

The utility function of the firm is:

$$
U=R+\widetilde{G}-(\beta-e)-K-\psi(e)
$$

where as described before $R$ are revenues, $\widetilde{G}$ is the grant, $(\beta-e)+K$ are total costs and $\psi(e)$ is the disutility of effort.

The Commission sets the grant with the goal of maximizing social welfare, the grant is financed with distortive taxation which creates a social cost $\lambda^{1}$. Consumers' net welfare from the project can be written as:

$$
V=S-R-(1+\lambda) \widetilde{G}
$$

\footnotetext{
${ }^{1}$ This assumption is just another way of saying that the EU puts more weight on consumer surplus than the firm's rent. As a consequence the Commission wishes to minimize the transfer from tax-payers to the firm.
} 
where $S$ is the surplus generated by the project, $R$ is the revenue (paid by consumers) and $(1+\lambda) \widetilde{G}$ is the total cost of the grant.

We assume (as in Laffont and Tirole [1993]) that total costs and revenues are expost observable and we make the accounting convention that the Commission receives the revenues, pays the costs and gives the firm a "net" grant:

$$
G=R+\widetilde{G}-(\beta-e)-K
$$

so that we simplify the expression for the firm's utility function to:

$$
U=G-\psi(e)
$$

We can also rewrite consumers' net welfare as:

$$
\begin{aligned}
V & =S-R-(1+\lambda)[G-R+(\beta-e)+K] \\
& =S+\lambda R-(1+\lambda)[(\beta-e)+K+\psi(e)]-(1+\lambda) U
\end{aligned}
$$

Social welfare is then:

$$
\begin{aligned}
W & =V+U \\
& =S+\lambda R-(1+\lambda)[(\beta-e)+K+\psi(e)]-\lambda U .
\end{aligned}
$$

If the Commission knew the true value of $\beta$ and could observe $e$ then the only constraint she would face is the participation constraint of the firm:

$$
U \geq 0
$$

Since giving up rent to the firm is costly (because of the marginal cost of public funds) the above constraint will be binding and the problem the Commission would solve in a world of perfect information becomes:

$$
\max _{e} W=S+\lambda R-(1+\lambda)[(\beta-e)+K+\psi(e)]
$$

From the FOC with respect to $e$ we find the first best level of cost reducing effort $e^{*}$ :

$$
\psi^{\prime}\left(e^{*}\right)=1
$$

which is that level that equates the marginal disutility of effort with the marginal benefit of effort (the marginal cost reduction effect), while from the binding participation 
constraint we obtain the first best grant:

$$
\widetilde{G}^{*}=\psi\left(e^{*}\right)+\left(\beta-e^{*}\right)+K-R .
$$

\subsection{The optimal grant}

Differently from the previous section we now assume that the Commission cannot observe $e$ and knows only the probability distribution of $\beta$.

We know that the grant can take the form of an optimal revelation mechanism which will apply the standard results of incentive theory.

The grant will be a contract conditional on the revelation of the efficiency parameter. In other words, a firm claiming to be efficient, i.e. of type $\beta$, will be offered a grant-cost reimbursement pair $\{(\underline{G}, \underline{c})\}$, while a firm which will reveal to be inefficient, i.e. of type $\bar{\beta}$, will be offered a pair $\{(\bar{G}, \bar{c})\}$. This contract is equivalent to the following $\{(\underline{U}, \underline{e}),(\bar{U}, \bar{e})\}$ that specifies, for every type of firm, an ex-post rent and an effort level.

The optimal grant will be designed satisfying two sets of constraints, the participation constraints of the previous section and the incentive compatibility constraints which will ensure the truthful revelation of the efficiency parameter by the firm.

The first set of constraints is:

$$
\begin{aligned}
& \underline{U} \geq 0 \\
& \bar{U} \geq 0 .
\end{aligned}
$$

Incentive compatibility constraints are:

$$
\begin{aligned}
& \underline{U}=\underline{G}-\psi(\underline{\beta}-\underline{c}) \geq \bar{G}-\psi(\underline{\beta}-\bar{c}) \\
& \bar{U}=\bar{G}-\psi(\bar{\beta}-\bar{c}) \geq \underline{G}-\psi(\bar{\beta}-\underline{c}) .
\end{aligned}
$$

The above inequalities make sure that an efficient firm will not gain from claiming to be inefficient and receiving the grant designed for the inefficient firm and vice-versa.

Let $\Phi(e)=\psi(e)-\psi(e-\Delta \beta)$ be an increasing and convex function of $e$.

Rewrite the IC of the efficient firm:

$$
\begin{aligned}
\underline{G}-\psi(\underline{e}) & \geq \bar{G}-\psi(\underline{\beta}-\bar{\beta}+\bar{e})+\psi(\bar{e})-\psi(\bar{e}) \\
\underline{G}-\psi(\underline{e}) & \geq \bar{G}-\psi(\bar{e})+\Phi(\bar{e}) \\
\underline{U} & \geq \bar{U}+\Phi(\bar{e})
\end{aligned}
$$


and the one for the inefficient firm:

$$
\begin{aligned}
\bar{G}-\psi(\bar{e}) & \geq \underline{G}-\psi(\bar{\beta}-\underline{\beta}+\underline{e})+\psi(\underline{e})-\psi(\underline{e}) \\
\bar{G}-\psi(\bar{e}) & \geq \underline{G}-\psi(\underline{e})-\Phi(\underline{e}+\Delta \beta) \\
\bar{U} & \geq \underline{U}-\Phi(\underline{e}+\Delta \beta)
\end{aligned}
$$

The optimal grant can now be derived by maximizing expected social welfare subject to the incentive compatibility and participation constraints. The program is:

$$
\begin{aligned}
& \max _{\{\underline{U}, \underline{e}, \bar{U}, \bar{e}\}} \nu[S+\lambda R-(1+\lambda)[(\underline{\beta}-\underline{e})+K+\psi(\underline{e})]-\lambda \underline{U}] \\
& +(1-\nu)[S+\lambda R-(1+\lambda)[(\bar{\beta}-\bar{e})+K+\psi(\bar{e})]-\lambda \bar{U}] \\
& \text { s.t.(14),(15),(18),(19). }
\end{aligned}
$$

In this type of problems the participation constraint of the inefficient firm (15) and the incentive compatibility constraint of the efficient (18) will be binding. We then have:

$$
\begin{aligned}
\bar{U} & =0 \\
\underline{U} & =\Phi(\bar{e}) .
\end{aligned}
$$

After substituting the above the optimization problem simplifies to:

$$
\begin{aligned}
& \max _{\{\underline{e}, \bar{e}\}} \nu[S+\lambda R-(1+\lambda)[(\underline{\beta}-\underline{e})+K+\psi(\underline{e})]-\lambda \Phi(\bar{e})] \\
& +(1-\nu)[S+\lambda R-(1+\lambda)[(\bar{\beta}-\bar{e})+K+\psi(\bar{e})]]
\end{aligned}
$$

From the FOC we obtain the required levels of cost reducing effort:

$$
\begin{aligned}
\psi^{\prime}\left(\underline{e}^{*}\right) & =1 \\
\psi^{\prime}(\bar{e}) & =1-\frac{\lambda}{1+\lambda} \frac{\nu}{1-\nu} \Phi^{\prime}(\bar{e}) .
\end{aligned}
$$

This is a standard solution that requires the efficient firm to carry out the optimal first best level of cost reducing effort while the level of effort required from an inefficient firm is lower than the first best because of the optimal trade-off between efficiency and informational rent. The departure from the efficient level of effort is greater when $\lambda$ is greater, that is when transferring more resources to the firm creates more distortive taxation. 
The grant offered to the two types of firms are the following:

$$
\begin{aligned}
\frac{\widetilde{G}}{\widetilde{G}} & =\Phi(\bar{e})+\psi\left(\underline{e}^{*}\right)+\left(\underline{\beta}-\underline{e}^{*}\right)+K-R \\
\widetilde{G} & =\psi(\bar{e})+(\bar{\beta}-\bar{e})+K-R
\end{aligned}
$$

and they are both higher than the first best grant, but for different reasons. $\widetilde{G}$ is higher because the Commission pays an informational rent $\Phi(\bar{e})$ to the efficient firm, while $\widetilde{\bar{G}}$ is higher because the level of cost reducing effort is inefficiently downward distorted and so the operating costs are higher. Asymmetric information between the European Commission and the firm makes project financing more expensive.

\subsection{The role of ex-ante and ex-post evaluators}

We now add to the above standard principal-agent model two additional players, the regional government and an ex-post evaluator.

The regional government pays a predefined share of the grant (co-payment) awarded by the Commission and covers a supervisory role. Because of its proximity to the firm the regional government is in fact assumed to have an informational advantage with respect to the Commission. We assume that, before the grant offer is made, the regional government receives a signal $\sigma$ about the efficiency status of the firm. This signal is observed by the firm. The regional government is non-benevolent and can be led by the firm into not disclosing information to the Commission in exchange of private benefits.

More than the local government being "crooks", this highlights the fact that the local interests and the supranational interests are not perfectly aligned.

The ex-post evaluator is sent, with some probability, by the Commission after the project has been built. If sent, the auditor will learn, with probability one, verifiable information about the parameter $\beta$. We make the further assumption that the ex-post evaluator has no discretion and cannot lie about what he has learned (i.e. cannot be corrupted), this again is to stress the difference between central and local interests and the ex-post evaluator is an extension of the benevolent higher level of government (the Commission). If the outcome of the valuation is that the firm has lied at a previous stage then there is a fine to pay.

The timing of our game is now the following:

1. the firm learns $\beta$;

2. the regional government learns $\sigma$; 
3. the Commission offers two contingent grants;

4. the firm chooses the grant;

5. grant is paid;

6. ex-post evaluator is sent with probability $p$;

7. possible fines to be paid.

Because this is a finite game we apply backward induction and start by studying the effect of the introduction of an ex-post evaluator.

Let $p$ be the probability of sending an ex-post auditor, $p^{2} H$ the cost of the audit and $P$ the exogenous punishment for the firm if it turns out it lied to the Commission ${ }^{2}$.

An optimal grant will now be a pair of triplets $\{(\underline{U}, \underline{e}, \underline{p}),(\bar{U}, \bar{e}, \bar{p})\}$, in other words the offer by the Commission will include contingent probabilities of audit together with a rent and effort level.

We will consider the punishment to be exogenous and not too high, so that the participation constraint will be satisfied.

It is worth stressing that there is no need to evaluate a firm claiming to be efficient, because the inefficient's type incentive constraint is slack anyway and auditing is costly. In other words, it will never happen that an inefficient firm claims to be efficient, hence, at an optimum, we necessarily have $p=0$.

The only constraint that needs to be modified is therefore the IC of an efficient firm:

$$
\underline{U}=\Phi(\bar{e})-\bar{p} P
$$

in other words, the benefit from an untruthful report are lowered by the probability of audit and the expected punishment. As a consequence also the informational rent that needs to be paid to ensure a truthful report is also reduced.

The role played by the regional government is instead more complex.

By assumption the signal $\sigma \in\{\varnothing, \underline{\beta}\}$, this means that the regional government either discovers the firm to be efficient or it will learn nothing from the signal. More precisely if $\beta=\beta$ the local government observes $\sigma=\underline{\beta}$ with probability $\xi$ and nothing with probability $1-\xi$. If $\beta=\bar{\beta}$ it does not observe anything.

We make the additional assumption that the signal $\sigma=\beta$ is hard information, meaning that it can be hidden but not manipulated.

\footnotetext{
${ }^{2}$ On delegated random auditing see Faure-Grimaud, Laffont and Martimort [1999] and Laffont and Martimort [2002].
} 
If the regional government was benevolent, then the Commission would be able to offer the first best grant when $\sigma=\beta$ and offer the second best contract with updated probability of the firm being efficient, given by $\widehat{\nu}=\frac{\nu(1-\xi)}{1-\nu}$, whenever $\sigma=\varnothing$ (that is when the regional government's signal is not informative).

We instead assume that the regional government is non benevolent and can be led by the local firm to conceal unfavorable evidence about the efficiency parameter ${ }^{3}$. Some private benefits paid by the firm would represent the gain for the regional government.

The firm is to stand losing the informational rent if evidence about $\beta=\underline{\beta}$ is brought forward to the Commission, this, after the introduction of random auditing by the ex-post evaluator, amounts to $\Phi(\bar{e})-\bar{p} P$. This implies that any payment $b$ that the firm might be willing to offer to the local government has an obvious upper bound:

$$
b \leq \Phi(\bar{e})-\bar{p} P .
$$

The utility function of the regional government is given by the sum of the regional consumer's net surplus plus the private benefit it might receive from the firm:

$$
L G=\widehat{S}-\widehat{R}-\alpha(1+\lambda) \widetilde{G}+k b
$$

where $\widehat{S}$ is the change in regional consumer surplus from the project, $\widehat{R}$ is the share of revenues paid by regional consumers, $\alpha$ is the share of the grant that the regional government will have to finance, $(1+\lambda) \widetilde{G}$ is the total cost of the grant as before, $b$ are private benefits and $k \in(0,1)$ is the efficiency of collusion. $k \in(0,1)$ implies that not all the funds spent by the firm arrive in the pockets of the regional government, this may be due to the transaction costs of such not-very-legal activity or to the nature of the goods exchanged.

To avoid collusion in equilibrium the Commission will have to pay some contingent transfer $m$ to the local government whenever it reports that the firm is efficient.

The incentive compatibility constraint for the local government is:

$$
\widehat{S}-\widehat{R}-\alpha(1+\lambda) \widetilde{G}^{*}+m \geq \widehat{S}-\widehat{R}-\alpha(1+\lambda) \underline{\widetilde{G}}+k b
$$

which ensures that the local government will prefer to report an efficient firm, receive $m$ and pay a share of $\widetilde{G}^{*}$ instead of hiding evidence, receive $k b$ and pay a share of $\widetilde{G}$.

\footnotetext{
${ }^{3}$ We model collusion in the spirit of Tirole [1979].
} 
This is a moral hazard constraint that will induce the regional government to behave like the Commission prefers. In other words, the Commission must compensate the regional government for its help in the evaluation of the project (and for giving up the transfer from the local firm), in this way truthful reporting about the firm parameters becomes convenient for the regional government.

After a few calculations we find:

$$
m \geq[k-\alpha(1+\lambda)](\Phi(\bar{e})-\bar{p} P) .
$$

So in case the firm is efficient and the regional government finds hard evidence about that, then the Commission does not pay any informational rent to the firm, instead it pays a transfer to the regional government. The gain for the Commission comes from $m$ being lower than $\underline{U}$ for two reasons:

1. inefficiency of collusion $(k<1)$

2. cost sharing between the Commission and the regional government (if the firm is efficient also the local government saves on his share of the grant)

Because of the incentives given to regional government to reveal information the solution will be the first best full-information one with probability $\nu \xi$, that is the probability that the firm is efficient and that the local government observes it.

More precisely the objective function for the Commission is now:

$$
\begin{aligned}
& \max _{\{\underline{U}, \underline{e}, \bar{U}, \bar{e}, \bar{p}\}} \nu \xi\left[S+\lambda R-(1+\lambda)\left[\left(\underline{\beta}-\underline{e}^{*}\right)+K+\psi\left(\underline{e}^{*}\right)\right]-\lambda m\right] \\
& +\nu(1-\xi)[S+\lambda R-(1+\lambda)[(\underline{\beta}-\underline{e})+K+\psi(\underline{e})]-\lambda \underline{U}] \\
& +(1-\nu)\left[S+\lambda R-(1+\lambda)[(\bar{\beta}-\bar{e})+K+\psi(\bar{e})]-\lambda \bar{U}-\bar{p}^{2} H\right],
\end{aligned}
$$

this is composed by three elements: with probability $\nu \xi$ the firm is efficient and the regional government observes a meaningful signal therefore the Commission compensates the regional government for its contribution, with probability $\nu(1-\xi)$ the firm is efficient but the regional government does not observe anything so the firm must be given some rent to reveal its parameters truthfully and finally with probability $(1-\nu)$ the firm is inefficient so the Commission will send an ex-post evaluator with probability $p$ and will pay the evaluation cost $\bar{p}^{2} H$. 
The constraints that the Commission has to satisfy are the following:

$$
\begin{aligned}
\bar{U} & =0 \\
\underline{U} & =\Phi(\bar{e})-\bar{p} P \\
m & =[k-\alpha(1+\lambda)](\Phi(\bar{e})-\bar{p} P)
\end{aligned}
$$

We have assumed that the firm observes the local government signal, more formally we can say that the information sets are nested. This implies that the constraints have to be satisfied in each state of the world. With probability $\nu \xi$ there is no asymmetric information anymore between the local government and the firm and, as we previously said, the first best grant and effort can be implemented. When the signal is not informative, and the firm is efficient, it must be given an informational rent that is lower if compared to the one in the previous section when the ex-post evaluator was not present.

From the FOC we obtain the following:

$$
\begin{aligned}
\psi^{\prime}\left(\underline{e}^{*}\right) & =1 \\
\psi^{\prime}(\bar{e}) & =1-\frac{\lambda}{1+\lambda} \frac{\nu}{1-\nu} \Phi^{\prime}(\bar{e})[(1-\xi)+\xi(k-\alpha(1+\lambda))] .
\end{aligned}
$$

In other words also when the firm is efficient and the local government does not receive and informative signal (that happens with probability $\nu(1-\xi)$ ) the cost reducing effort required is the efficient level, what is different are the costs for the Commission which are now higher because $\underline{U}>m$. The informational rent for an efficient firm is in fact higher than the transfer required to have a truthful report from the regional government.

In case of an inefficient firm the cost reducing level of effort is distorted away from the efficient level, but it is less distorted than in the case without the regional government.

So the grant awarded by the European Commission will be the following contingent plan:

$$
\begin{array}{ll}
\begin{array}{ll}
\text { with probability } \nu \xi & : \widetilde{G}^{*}=\psi\left(e^{*}\right)+\left(\beta-e^{*}\right)+K-R
\end{array} \\
\begin{array}{ll}
\text { with probability } \nu(1-\xi): & \widetilde{\widetilde{G}}=\Phi(\bar{e})-\bar{p} P+\psi\left(\underline{e}^{*}\right)+\left(\underline{\beta}-\underline{e}^{*}\right)+K-R \\
\text { with probability }(1-\nu) & : \widetilde{\bar{G}}=\psi(\bar{e})+(\bar{\beta}-\bar{e})+K-R
\end{array}
\end{array}
$$

The presence of the regional government has an effect also on the probability of 
sending an ex-post auditor, the optimal probability is:

$$
\bar{p}=\frac{\lambda \nu}{1-\nu} \frac{P}{2 H}[(1-\xi)+\xi(k-\alpha(1+\lambda))]
$$

which is decreasing in $\xi$, the precision of the signal received by the regional government.

It is now evident how the European Commission may benefit from ex-ante and ex-post evaluators when making grant decisions. The presence of an ex-post evaluator and the potential punishment contribute to the reduction of the informational rent that must be given to the firm to ensure truthtelling, this has a direct effect on the grant which is equally reduced.

An indirect effect comes from the fact that the stake of collusion between the firm and the regional government is reduced. In other words the amount of resources that the firm may loose if the regional government reports everything it has learned is now lower, as a consequence the sum available to contribute private benefits to the regional government is also reduced. This makes fighting collusion a bit cheaper for the Commission.

The presence of the regional government acting as an ex-ante evaluator also brings benefits and savings to the Commission. The reason is that, in the event of a meaningful signal received by the regional government, it is cheaper to obtain truthful revelation from the regional government than from the firm itself. This is due to the inefficiency of collusion which gives the Commission and advantage over the firm when transferring funds to the regional government and to the co-payment of the grant which realigns, a least in part, the incentives of the regional government and those of the Commission.

\subsection{Some comparative statics}

The EU structural funds are destined to the financing of projects in all of the member states which are likely to differ under many and important aspects. Some of the parameters of the model can be used to take into account some possible differences and to evaluate how the optimal decision by the Commission will vary.

1. The copayment share $\alpha$. The percentage of the project which is to be financed by the regional government is not fixed. It will vary from region to region and everything equal it is likely to be higher in richer member states (typically the "old" members). As $\alpha$ increases the interests of the regional government will be more in line with those of the Commission implying that it is easier 
for the latter to fight collusion at the evaluation stage. To the contrary the regional governments of the new member states must be given a more generous compensation to carry out the evaluation task. Adding to the higher share financed by the Commission this makes the financing of projects in the new member states relatively more expensive than in the old member states.

2. The efficiency of collusion $k$. Diverting funds into the hands of local politicians can be more easily done in some states than in others. In some countries where the regional governments are used to obtain private benefits from the political activity it will be easier for the firm to convince the regional government to conceal some evidence about its efficiency parameters. This means we will face a higher $k$ that will take various forms: the presence of many channels in which funds can flow from firms to politicians and administrators, higher tolerance from the public, less efficiency of the regional police in fighting corruption or an easier way to transform the given goods and services into money. Those countries with a lower $k$ (but with similar growth opportunities), those that are less prone to collusion, will be a more fertile ground for the Commission grant. Lower sums will achieve better projects. ${ }^{4}$

3. The precision of the signal $\xi$. The probability with which regional governments observe the cost parameters of the firm may be different across countries. As $\xi$ increases towards one we observe two effects:

1. the first best will be implemented more often;

2. the distortion in cost reducing effort is lower.

Project in member states where regional governments are better at acquiring information ${ }^{5}$ will be more efficient to implement and less expensive to finance.

4. The cost of ex-post evaluation $H$. Accounting procedures and certification standards vary across member states. It is therefore reasonable to assume that the cost of ex-post evaluation will be lower in those states where the information for financial and economic analysis of projects is more complete and credible. Clearly the probability of an ex-post evaluation increases as the cost of the audit decreases, contributing therefore to the reduction of the grant necessary to finance the project carried out by an efficient firm.

\footnotetext{
${ }^{4}$ In principle empirical testing or simulations can be done by proxying $k$ with a governance index, such as the one proposed by Kaufman ,Kray and Mastruzzi [2005].

${ }^{5}$ This can be proxied, for example, by the human capital available in the public sector.
} 
5. The difference in efficiency $\Delta \beta$. The higher is $\Delta \beta$, that is the higher the difference in the operating costs of the implementing firm, the higher the distortions. In particular, the importance of eliciting information about an technology with lower costs becomes more important, and as a consequence the informational rent is higher. This has an effect on the level of cost reducing effort (lower) and of the grant (higher). The optimal contract will therefore implement a less distortive outcome in regions where firms are more homogeneous.

\section{Conclusions}

Our model contributes to the application of incentive theory in a multi-government setting by focusing on a co-financing grant decisions in the context of regional policies. Our results show the optimal incentive contract for the grant, under an exogenous sharing of it between a supra-national planner and a local authority. We also how ex-ante and ex-post evaluation, as in fact embodied in some legislation, can critically contribute to contain socially costly rents. To do so, however, the contract between the EC (or any supra-national benevolent development agency) should establish a formal mechanism of rewards and punishments.

The regional government, who is responsible for ex-ante evaluation, should be paid to disclose ex-ante information on the firm and to avoid collusion. There should be a punishment following ex-post evaluation when the firm has been discovered to be more efficient than it claimed ex-ante.

We claim that fairly standard incentive theory provides a sound basis for understanding how different players interact in an investment planning game. We assume that each player acts to maximize his or her particular objectives. Having two governments, one supra-national and benevolent and the other one, more informed but with a private agenda, adds complexity to the principal-agent framework, but is realistic.

Our story have simple and important policy implications, that go beyond the European Union regional policy context. First, we show that ex-ante revelation of information to a federal government or a supra-national body by the region should be considered as a specific contract between the centre and the regional body. Second, the capital grant must be endogenous even when the co-payment share is exogenous. Rigid grant ceilings linked to investment costs, as often seen in matching-grant legislation in federations are inefficient. In fact these are cost-reimbursement rules that provide the wrong incentives to decentralised governments and executing agencies. The optimal grant depends upon region-specific parameters, hence it must vary 
across regions. Third, ex-post evaluation is a crucial mechanism in order to contain rents, and we have shown in a precise sense how ex post project evaluation raises the efficiency of hierarchical contracting in a multi-government context with a co-payment mechanism between the different layers of government.

\section{References}

[1] Akai N., and E. Silva (2009) "Interregional redistribution as a cure to the soft budget syndrome in federations", International Tax and Public Finance, 16(1):43-58.

[2] Bordignon, M. , P. Manasse and G. Tabellini (2001), "Optimal regional distribution under asymmetric information", American Economic Review, 91(3): 709-723

[3] Breuillè, M.L. and R.J. Gary-Bobo (2007) "Sharing budgetary austerity under free mobility and asymmetric information: An optimal regulation approach to fiscal federalism"; Journal of Public Economics, 91(5-6):1177-1196.

[4] Bucovetsky, M., M. Marchand and P. Pestieau (1998) "Tax competition and revelation of preferences for public expenditure", Journal of Urban Economics, 44:367-390.

[5] Caillaud, B., B. Jullien and P. Picard, (1996), "Hierarchical organization and incentives.", European Economic Review,40(3-5): 687-695

[6] Cornes R.C. and E.C.D. Silva (2002) "Local public goods, inter-regional transfers and private information", European Economic Review, 46:329-356.

[7] De Marzo, P., M.J. Fishman and K.M. Hagerty (2005) "Self-regulation and government oversight", Review of Economic Studies, 72(3):687-706.

[8] European Commission, (2006) "Guidance on the methodology for carrying out cost-benefit analysis", Working Document n.4, DG for Regional Policy, http://ec.europa.eu/regional_policy/index_en.htm

[9] European Commission (2007) Growing regions, Growing Europe. Fourth report on economic and social cohesion, Bruxelles. 
[10] Faure-Grimaud, A., J.J. Laffont and D. Martimort (1999) "The endogenous transaction costs of delegated auditing", European Economic Review 43:10391048

[11] Florio M., Vignetti S.,(2006) "Cost-benefit analysis of infrastructure projects in an enlarged European Union: return and incentives", Economic Change and Restructuring, 38: 179-210

[12] Huber, B. and M. Runkel (2006) "Optimal design of intergovernmental grants under asymmetric information", International Tax and Public Finance, 13(1):2541.

[13] Kaufman ,Kray and Mastruzzi (2005), "Governance Indicators for 1996-2004', http://info.worldbank.org/governance/kkz2004/

[14] Laffont, J.J. (2005) Regulation and Development, Cambridge University Press

[15] Laffont, J.J. and David Martimort (2002) The Theory of Incentives, Princeton Univ.Press

[16] Laffont, J.J. and J. Tirole (1993), A theory of incentives in regulation and procurement, MIT Press, Cambridge MA

[17] Lockwood, B. (1999) "Inter regional insurance", Journal of Public Economics, $72: 1-37$.

[18] Martimort, D. (1996), "Multiprincipaux avec anti-sélection", Annales d'Economie et de Statistique, 32:1-38

[19] Martimort, D. (1996), "The multiprincipal nature of government", European Economic Review, 0(3-5): 673-686

[20] Melumad N.D., D. Mookherjee and Stefan Reichelstein (1995) "Hierarchical decentralization of incentives contracts", RAND Journal of Economics, 26(4):654672

[21] Mookherjee, D. (2006), "Decentralization, Hierarchies and Incentives: A Mechanism Design Perspective", Journal of Economic Literature, 44(2):367-390

[22] Tirole, J. (1979) "Hierarchies and bureaucracies: On the role of collusion in organizations", Journal of Law, Economics and Organization 2:181-214. 
[23] Wren, C. (2003), "Informational rents and discretionary industrial assistance", mimeo 